OPEN ACCESS

Approved by:

Frontiers in Immunology Editorial

Office,

Frontiers Media SA, Switzerland

*Correspondence:

V. Sukumaran

drvsukumar@gmail.com

Se Chang Park

parksec@snu.ac.kr

†Present Address:

V. Sukumaran,

Department of Zoology, Kundavai Nachiyar Government Arts College for

Women (Autonomous), Thanjavur,

Tamil Nadu, India

\#These authors have contributed equally to this work

Specialty section

This article was submitted to Comparative Immunology,

a section of the journal

Frontiers in Immunology

Received: 29 August 2018 Accepted: 05 September 2018 Published: 26 September 2018

Citation:

Giri SS, Yun S, Jun JW, Kim HJ, Kim SG, Kang JW, Kim SW, Han SJ,

Sukumaran V and Park SC (2018)

Corrigendum: Therapeutic Effect of Intestinal Autochthonous Lactobacillus reuteri P16 Against Waterborne Lead

Toxicity in Cyprinus carpio.

Front. Immunol. 9:2208.

doi: 10.3389/fimmu.2018.02208

\section{Corrigendum: Therapeutic Effect of Intestinal Autochthonous Lactobacillus reuteri P16 Against Waterborne Lead Toxicity in Cyprinus carpio}

\author{
Sib Sankar Giri 1,2‡, Saekil Yun ${ }^{1 \neq}$, Jin Woo Jun ${ }^{1}$, Hyoun Joong Kim ${ }^{1}$, Sang Guen Kim ${ }^{1}$, \\ Jeong Woo Kang ${ }^{1}$, Sang Wha Kim ${ }^{1}$, Se Jin Han ${ }^{1}$, V. Sukumaran ${ }^{2 *}$ and Se Chang Park ${ }^{1 *}$ \\ ${ }^{1}$ Laboratory of Aquatic Biomedicine, College of Veterinary Medicine, Research Institute for Veterinary Science, Seoul National \\ University, Seoul, South Korea, ${ }^{2}$ Department of Biotechnology, Periyar Maniammai University, Thanjavur, India
}

Keywords: probiotics, lactic acid bacteria, $\mathrm{Pb}$, common carp, oxidative stress, immune parameters, gene expression

\section{A Corrigendum on}

Therapeutic Effect of Intestinal Autochthonous Lactobacillus reuteri P16 Against Waterborne Lead Toxicity in Cyprinus carpio

by Giri SS, Yun S, Jun JW, Kim HJ, Kim SG, Kang JW, et al. Front. Immunol. (2018) 9:1824. doi: 10.3389/fimmu.2018.01824

There is an error in the Funding statement. The correct number for the Cooperative Research Program for Agriculture Science and Technology Development (Supportive managing project of Center for Companion Animals Research) by Rural Development Administration is PJ013985032018.

The authors apologize for this error and state that this does not change the scientific conclusions of the article in any way.

Conflict of Interest Statement: The authors declare that the research was conducted in the absence of any commercial or financial relationships that could be construed as a potential conflict of interest.

Copyright $\odot 2018$ Giri, Yun, Jun, Kim, Kim, Kang, Kim, Han, Sukumaran and Park. This is an open-access article distributed under the terms of the Creative Commons Attribution License (CC BY). The use, distribution or reproduction in other forums is permitted, provided the original author(s) and the copyright owner(s) are credited and that the original publication in this journal is cited, in accordance with accepted academic practice. No use, distribution or reproduction is permitted which does not comply with these terms. 